\title{
A EDUCAÇÃo AMBIENTAL NAS REPRESENTAÇÓES SOCIAIS DE PROFESSORES E A IMPORTÂNCIA do Projeto Sala Verde
}

\author{
ENVIRONMENTAL EDUCATION IN THE SOCIAL REPRESENTATIONS \\ OF TEACHERS AND THE IMPORTANCE OF THE GREEN ROOM \\ Project
}

\author{
Iraelza Fátima Coelho Monteiro \\ Mestre em Desenvolvimento Humano pelo \\ Programa de Educação e Desenvolvimento Humano da UNITAU, Taubaté-SP, Brasil \\ ORCID: https://orcid.org/0000-0001-5413-8804 \\ profiraelza@gmail.com
}

\begin{abstract}
Patrícia Diana Edith Belfort de Souza Camargo Ortiz Monteiro
Doutora em Ciências Ambientais pela Universidade de Taubaté. Professora do Programa de Educação e Desenvolvimento Humano da UNITAU, Taubaté-SP, Brasil ORCID: https://orcid.org/0000-0002-2944-9050 patyortizmonteiro@terra.com.br
\end{abstract}

Resumo: Este artigo refere-se a uma pesquisa quali-quantitativa voltada à análise das representaçóes sociais sobre Educação Ambiental (EA) de professores no Ensino Fundamental II. Focaliza o Projeto Sala Verde, coordenado pelo Departamento de Educação Ambiental do Ministério do Meio Ambiente, que tem por objetivo difundir espaços socioambientais nos municípios brasileiros, entre os quais o município de Taubaté, no Vale do Paraíba paulista, universo desta pesquisa. A coleta de dados foi realizada em duas etapas: primeiro, 388 professores responderam a um questionário e, posteriormente, 7 docentes participaram de entrevistas. Os textos foram sistematizados no programa Alceste e classificados em agrupamentos de discurso. Neste artigo, foram analisadas duas classes que organizam as representaçóes dos professores a partir da relevância conferida por eles à EA. Os resultados indicam a importância da formação continuada para a efetivação da EA nas escolas de forma interdisciplinar.

Palavras-chave: Educação Ambiental. Projeto Sala Verde. Representaçóes Sociais.

Aвstract: Here, we use a quali-quantitative approach to analyze the social representations of Environmental Education (EE) of teachers in Elementary School II. We focus on the Green Room Project, coordinated by the Department of Environmental Education of the Ministry of the Environment, which aims to disseminate socio-environmental spaces in Brazilian municipalities, including Taubaté, in the Paraíba Valley of São Paulo, which is the subject of this study. Data collection was performed in two stages: first, we applied 
the questionnaire to 388 teachers and, subsequently, 7 teachers were selected for the interview. The texts were systematized in Alceste software and classified into discourse groups. We analyze two classes that organize the teachers' representations according to the importance given by them to EE. The results show the importance of continuing education for the implementation of EE in schools in an interdisciplinary way.

KeYwords: Environmental Education. Green Room Project. Social Representations.

\section{Introduçáo}

Um dos objetivos fundamentais da Educação Ambiental (EA) é exercer um papel essencial na relação intrínseca do homem com o meio ambiente, vivenciada de forma coletiva ou individual. A EA apresenta marcas características do pensamento ecologista, incluindo nele aspectos próprios das limitaçóes humanas (REIGOTA, 2011), assim representando a somatória de diversos elementos coexistindo numa mesma teia.

No Brasil, a questão ambiental se intensifica nos discursos e nos estudos ao longo da década de 1960, após uma fase de intenso crescimento urbano. Com a crise do petróleo no final dessa década e início da de 1970, iniciam-se reflexôes acerca do futuro que se apresentava incerto, instigando o pensamento político, social e filosófico, inquirindo acerca da participação do homem no planeta (BRASIL, 1995). Nesse contexto, começaram as discussóes e estudos acerca da Educação Ambiental.

No mundo, a década de 1970 marcou também a amplificaçáo do uso do termo ecologia, que começou a ser divulgado para a populaçáo e passou a ser reconhecido pela sociedade em geral (BRASIL, 1997, p.176). Desde então, estudos, projetos e pesquisas se intensificaram com a pretensão de ampliar o olhar para a EA nas instituiçôes educacionais. A primeira conferência intergovernamental sobre EA, realizada em Tbilisi no ano de 1977, estabeleceu princípios norteadores, objetivos e estratégias para que a EA se consolidasse enquanto prática pedagógica. (LOUREIRO, 2009).

Em meados dos anos 1980, ocorreram vários eventos marcantes, em âmbitos internacional e nacional, voltados à EA no sentido de discutir e consolidar "pactos políticos sobre as questôes ambientais" (BUSSOLOTI; ORTIZ, 2015, p.15), numa perspectiva de solidificar as ações. Um desses eventos foi a criaçáo da Lei Federal no 6.938, sancionada em 1981, que estabeleceu a Política Nacional de Meio Ambiente (PNMA), determinando 
aos estados e aos municípios a responsabilidade de executar açóes parceiras entre os órgãos que visassem à proteção ao meio ambiente. A PNMA contemplou a EA numa dimensão que destaca o processo educativo como dinâmico, integrativo, permanente e transformador, alinhando-se à abordagem da EA segundo os preceitos estabelecidos em Tbilisi e vislumbrando uma EA com ênfase na aquisição de conhecimentos e habilidades de forma participativo-ativa e crítico-social (BRASIL, 2014). Além disso, em abril de 1999 foi sancionada a Lei Federal 9.795/99, que estabelece que a EA deva estar presente, de forma articulada, em todos os níveis e modalidades do processo educativo. (Artigo 26, $\$ 7 \mathrm{da}$ LDB)

Desde a criação da PNMA, várias outras leis, estudos, projetos e ações foram desenvolvidas por entidades da sociedade civil e instituiçóes públicas no sentido de instrumentalizar a EA, compreendida como tema transversal e importante propulsora de aprendizagem significativa. Também como resultado desse processo foi criado o projeto Sala Verde, cujo objetivo era difundir espaços socioambientais nos municípios e desenvolver atividades interativas de EA com professores e munícipes. O Projeto Sala Verde, coordenado pelo Departamento de Educação Ambiental do Ministério do Meio Ambiente (DEA/MMA, 2000), teve seu início em consequência da demanda de diversos municípios e instituiçóes por possuir um Centro de Referência em Informaçôes Ambientais que possibilitasse o acesso às diversas publicações produzidas e/ou disponibilizadas pelo MMA.

Diante desse cenário, em 2013 foi criada a Sala Verde no município onde se realiza esta pesquisa, localizado no Vale do Paraíba paulista, espaço denominado Centro Municipal de Referência em Educação Ambiental (CEMREA) e, a partir de entáo, encontros entre professores da rede municipal de ensino vêm sendo realizados nesse espaço. A Sala Verde desse município está centrada em uma das escolas afiliadas à rede municipal de Ensino Infantil e Ensino Fundamental I e II, situada na zona urbana. No espaço destinado ao Projeto, disponibiliza-se acesso a arquivos digitais e livros sobre o grande tema Meio Ambiente (MA) e EA, para fins de pesquisa de professores, alunos e dos munícipes em geral.

Realizaram-se, a partir da e motivados pela Sala Verde, encontros de aperfeiçoamento, por meio de capacitaçóes com profissionais especialistas na área de Educação Ambiental, como funcionários da Secretaria de Meio Ambiente do município para ministrar oficinas e palestras aos professores 
do grupo de estudos de EA. De 2013 a 2016 foram realizados vários eventos, podendo-se destacar a oficina sobre a Comissão de Meio Ambiente e Qualidade de Vida (COM-VIDAS), Oficina do Futuro, além de palestras, construção de maquetes, cursos de extensão, construção de mini viveiro de mudas e a Conferência Municipal do Meio Ambiente.

Nesse sentido, o Projeto Sala Verde permitiu o desenvolvimento de um processo de formação continuada dos professores, trazendo as discussôes de EA para as escolas do município. Segundo Edgar Morin (2000), o educador tem condiçóes especiais para desenvolver a EA e explorá-la como uma filosofia de vida desenvolvida por meio de açóes que favoreçam as transformaçóes coletivas. A EA, para o autor, nada mais é que a própria educação incorporada na rotina da escola como um instrumento que visa garantir a sustentabilidade e a melhoria da qualidade de vida. Nessa perspectiva, a partir da inserção de melhores estratégias de ensino no campo da EA, torna-se viável atuar coletiva e satisfatoriamente na problemática socioambiental.

A formação do homem enquanto cidadão precisa estar pautada na busca por desenvolver açóes que conduzam à prática de um consumo consciente, à necessidade de se fazer economia para garantir a própria manutenção das espécies que co-habitam o planeta, com vistas à sustentabilidade deste para as geraçôes futuras. Para Reigota (1995), a convivência harmoniosa entre os seres e os recursos naturais dar-se-à por meio de promoção e estímulos aos cidadãos para participação nas discussốes e reflexôes socioambientais que promovam a busca do desenvolvimento sustentável. Nessa direção, a EA se fez necessária como importante instrumento para auxiliar no processo de transformação do ser humano, favorecendo a construção de novos saberes sustentáveis e transformando mentes.

Sendo assim, torna-se importante um trabalho incisivo de EA empreendido por meio de estímulos ao desenvolvimento do sentimento de identificação com o próximo e com o meio ambiente, estímulos ao amadurecimento da espécie humana por um processo de conscientização para que o nosso comportamento seja econômico e, consequentemente, ecológico.

Sob essas perspectivas teóricas, delineou-se a investigação retratada neste estudo, que buscou compreender, por meio das representaçóes sociais dos docentes, o processo pedagógico de desenvolvimento da EA nas unidades escolares. 


\section{Metodologia}

Este estudo caracteriza-se por apresentar abordagem qualitativa e quantitativa com escopo descritivo, dimensão exploratória e natureza aplicada. Tem por finalidade compreender as representaçóes sociais (doravante RS) dos professores da rede municipal de ensino no que concerne ao desenvolvimento da Educação Ambiental realizada nas suas unidades escolares. O procedimento de análise foi realizado à luz da Teoria das Representações Sociais (TRS), de Moscovici (2011), precursor da teoria que fundamenta a teoria analítica aqui empreendida.

De acordo com o conceito de Moscovici (2011), representar é buscar na memória uma imagem pré-concebida ou conclusôes passadas e retratálas, aproximando-a ao máximo da realidade desconhecida.

Essas representaçóes são fenômenos que se manifestam com a finalidade de preencher um vazio ameaçador. Assim, para que sejam saciados os conflitos da incerteza que possa limitar a estrutura de um grupo conforme ressalta Moscovici (2011), "um enorme estoque de palavras, que se referem a objetos específicos circulam na sociedade para que sejam transformadas em representaçóes concretas para satisfazer, com igual valor, o vazio, antes ameaçador." (MOSCOVICI, 2011, p. 71-72).

O presente estudo expóe duas etapas de coleta de dados, apresentadas cronologicamente neste artigo. A primeira etapa deu-se no âmbito do Projeto Sala Verde, que propiciou a aplicação de um questionário cujo intuito era diagnosticar as dificuldades encontradas na prática da EA nas escolas. Os 388 sujeitos que participaram voluntariamente desta etapa compóem o quadro docente de escolas do ensino básico (Infantil e Fundamental I e II) situadas nas diferentes áreas geográficas do município estudado, integrando unidades da área rural e urbana. $\mathrm{O}$ questionário foi aplicado no Horário de Trabalho Pedagógico Coletivo (HTPC), sob a supervisão do gestor escolar, contendo cinco perguntas objetivas, com a possibilidade de assinalar apenas uma resposta. Na segunda etapa, alguns professores foram convidados a participar de entrevistas em profundidade. (E AQUI TEMOS UMA AMOSTRA DE X \% DO UNIVERSO DE 388 PARA UMA ABORDAGEM QUALITATIVA) Participaram, então, 7 professores do Ensino Fundamental II que ministram aulas do $6^{\circ}$ ao $9^{\circ}$ ano nas disciplinas de Ciências, Artes, Geografia, Matemática, 
Língua Portuguesa e Inglês. Os textos coletados nas entrevistas foram sistematizados e analisados pelo programa Analyse Lexicale par Contexte d'um Exemple de Segmentes de Texte (Alceste), software criado na década de 1970 que analisa os dados textuais transcritos a partir de três etapas: a) leitura do texto; b) classificação das unidades de contexto; e c) descrição da classificação efetuada. Para fins deste estudo, foram selecionadas duas classes mais significativas para análise.

\section{Resultados da Etapa 1}

As figuras de 1 a 5 apresentam gráficos contemplando os resultados referentes aos questionários que fizeram parte deste estudo. Na Figura 1 são apresentados os resultados da questáo que visava identificar a facilidade em relação ao trabalho com a temática ambiental em sala de aula e/ou na unidade escolar. Dos 388 professores que responderam ao questionário, 335 indicaram que sim, possuem facilidade em trabalhar com a temática EA nas escolas, o que corresponde a $86,34 \%$ dos pesquisados. Considerando o universo total de professores, apenas $13,14 \%$ deles, o equivalente a 51 docentes, responderam que não possuem facilidade de trabalhar com EA, e apenas 2 não responderam à essa pergunta.

A Figura 2 contabiliza quantas vezes por semana são realizadas atividades voltadas à EA na escola. Quando indagados sobre a frequência semanal de atividades envolvendo a temática ambiental, 127 professores, ou $32,73 \%$ dos 388 respondentes, afirmaram que o fazem uma vez por semana; 87 professores $(22,42 \%)$ indicaram uma frequência maior, pois trabalham temas ambientais ao menos duas vezes por semana.

Interessante observar que muitos docentes, o equivalente a $38,40 \%$ do grupo, afirmaram abordar temas ambientais mais de duas vezes por semana, somando 149 professores com essa prática, o que valoriza o trabalho com tais temáticas. Outros 17 professores $(4,38 \%)$ responderam que náo trabalham com ela nenhuma vez por semana (entram aqui aqueles que nunca abordam esse tema e aqueles que abordam eventualmente) e, por fim, 8 ou 2,06\% dos professores não souberam ou não quiseram responder a essa questão. 


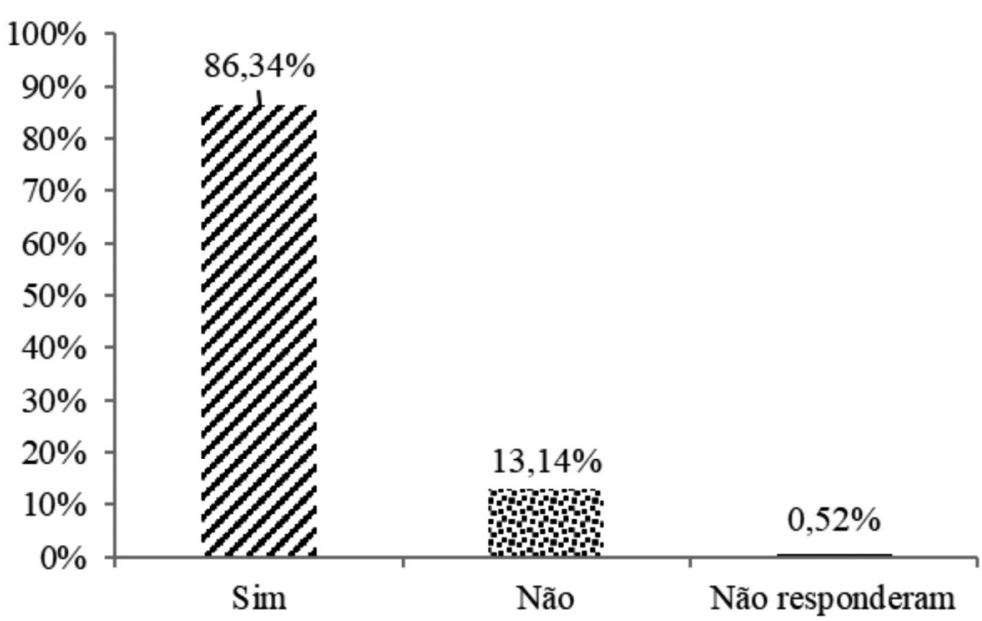

Figura 1: A sua unidade escolar tem facilidade para trabalhar a EA? Fonte: As autoras, 2017.

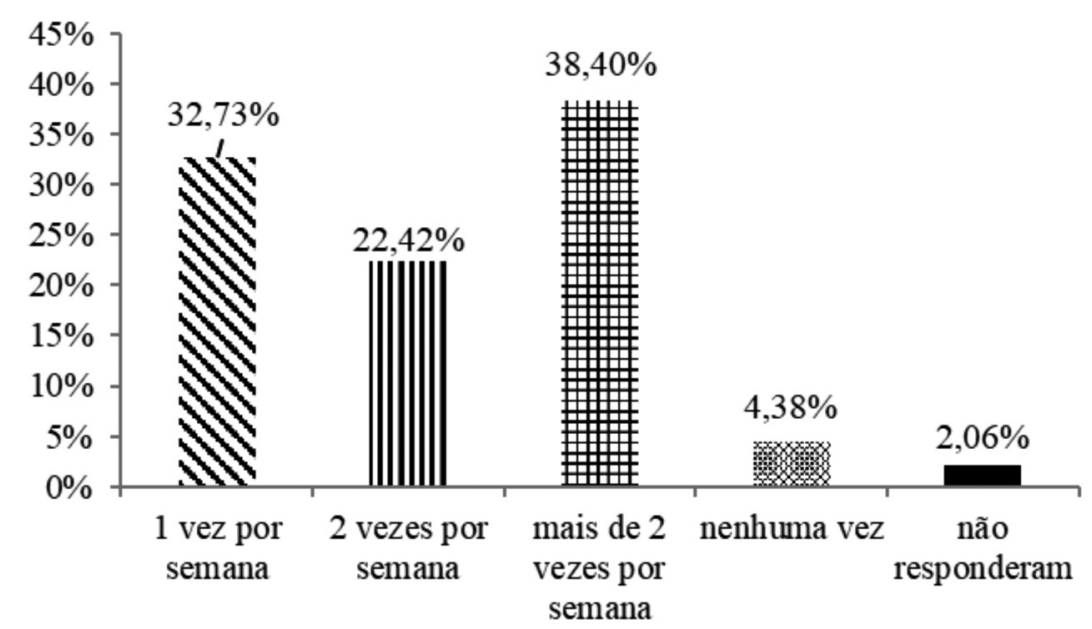

Figura 2: Quantas vezes por semana se trabalha com a temática EA? Fonte: As autoras, 2017.

Os professores manifestaram que possuem estímulos e/ou facilidades para desenvolver um trabalho efetivo em torno da temática ambiental, no entanto, quando se afere a frequência semanal com que des- 
pendem esforços no intuito de efetivar as oportunidades encontradas, apenas 38,40\% deles manifestam que se empenham em realizar atividades com a EA mais de duas vezes por semana na escola. Esse dado nos levam a inferir que, a despeito da oportunidade anunciada, ou mesmo da liberdade para o desenvolvimento da EA, não se traduz em atividades efetivas no ambiente escolar.

$\mathrm{Na}$ Figura 3 apresentam-se os dados referentes ao trabalho de temas ambientais, na perspectiva da EA, em reunióes de HTPC, que podem ser voltadas para a formação continuada dos professores e da equipe de gestão.

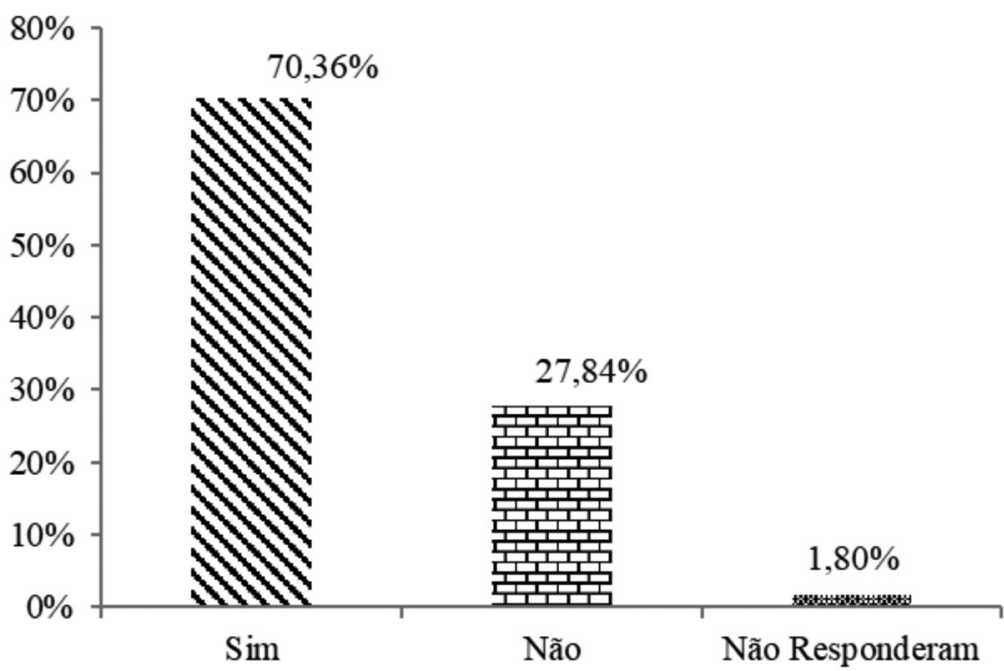

Figura 3: No HTPC já foi abordado o tema EA?

Fonte: As autoras, 2017.

A grande maioria dos professores que respondeu ao questionário indicou resposta afirmativa em relação ao trabalho de temas ambientais em reunióes de HTPC: foram 273 docentes, o que equivale a 70,36\% do total; a resposta negativa foi dada por 108 professores, portanto, 27,84\% dos docentes responderam que o tema não foi abordado em HTPC. Não souberam ou não quiseram responder a essa pergunta 7 professores. 
O fato de mais de dois terços dos professores apontar para a abordagem dos temas ambientais nos momentos de trabalho e planejamento coletivos reafirma o estímulo/facilidade que os professores alegaram encontrar em relação ao desenvolvimento de atividades na EA. Por outro lado, o fato de a maioria dos professores alegarem que pouco ou nada dedicam das suas aulas às temáticas ambientais reforça a inércia existente entre os professores no que diz respeito à abordagem transversal e interdisciplinar que caracteriza a $\mathrm{EA}$, prevalecendo o tecnicismo marcado pela segregação/compartimentação do conhecimento em conteúdos disciplinares.

Salienta-se a importância dos estudos em HTPC cuja finalidade seja articular as diferentes áreas do conhecimento na promoção e troca reflexiva de experiências entre os profissionais da educação, na busca por tornar viável a prática docente analisada em comum dentro do grupo (NÓBREGA; CASAVECHIA, 2008). Nesse contexto, os resultados apontam que a inserção do tema EA como estudo inerente ao HTPC gerou discussão e questionamento entre os professores, estimulando a formação.

As figuras 4 e 5 organizam as respostas dadas nos questionários em relação ao trabalho efetivo com a EA em sala de aula.

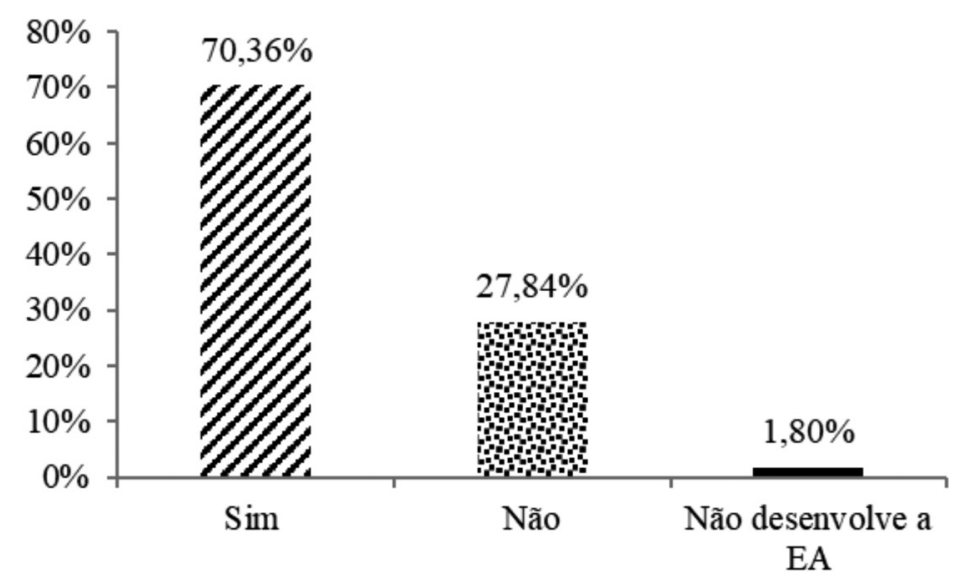

Figura 4: Como os professores desenvolvem EA na escola - Nos conteúdos curriculares

Fonte: As autoras, 2017. 
No que concerne ao desenvolvimento de atividades envolvendo a EA incorporada aos conteúdos curriculares os professores responderam o que pode ser observado na Figura 4. Questionados se utilizam dos conteúdos curriculares de suas disciplinas para abordar a EA, percebeu-se que 273 professores $(70,36 \%)$ alegam utilizar os conteúdos curriculares para tal abordagem; já 108 professores (27,84\%) afirmam que abordam a EA, mas não nos conteúdos curriculares de suas respectivas disciplinas, e outros 7 professores $(1,8 \%)$ alegaram náo abordar a EA em sala de aula.

Ao analisar os resultados que indicam abordagem fragmentada dos conteúdos que opóe a interdisciplinaridade e o tradicional trabalho isolado, conforme comprova o Gráfico 4, este estudo trouxe à luz que ainda há pouca ou quase nenhuma articulação entre os conteúdos teóricos e as tarefas desenvolvidas nas salas de aula "ou seja, a formação inicial dos professores não é capaz de colocar no mercado de trabalho profissionais com conhecimentos e instrumentos básicos para desenvolver a contento sua atividade" (SETUBAL, 2015), principalmente no que se refere às propostas pedagógicas que motivam a interdisciplinaridade.

Em relação à abordagem da EA por meio de projetos individuais ou projetos coletivos, os professores acenaram para o que se pode observar na Figura 5.

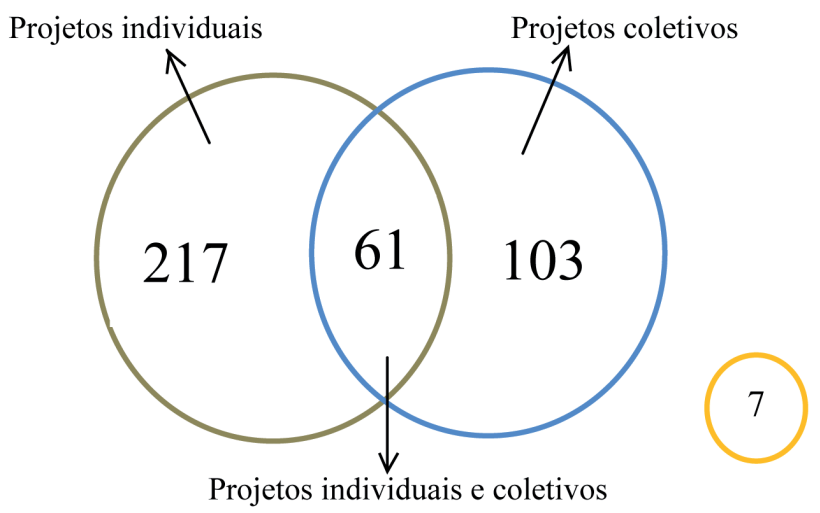

Figura 5: Como os professores desenvolvem EA na escola - Em projetos individuais ou coletivos

Fonte: As autoras, 2017. 
Ao investigar se os professores fazem uso de projetos para a abordagem da EA com a seus alunos, 217 professores alegaram aborda-la apenas em projetos que desenvolvem individualmente, não abarcando outras disciplinas ou docentes; 103 professores alegaram que desenvolvem a EA apenas por meio de projetos coletivos e 61 alegaram que abordam a EA por meio de projetos que desenvolvem de forma individual e coletiva. Os 7 respondentes restantes alegaram que náo desenvolvem nenhum tipo de projeto, tampouco abordam a EA em suas aulas.

O fato de 164 professores, dentre os 388 respondentes, informarem que abordam a EA em projetos individuais, indica que há uma característica tecnicista e fragmentada da concepção de EA que acaba por realçar o modelo de ensino tradicional no qual o professor foi formado. Tal representação desvela uma tendência de manutenção da ordem estabelecida, esvaziando o processo transversal, reflexivo e crítico que marca a EA. Em contrapartida, o fato de 278 professores sinalizarem para a abordagem da EA com projetos coletivos, significa que há indicativos de que esses professores manifestaram uma tendência de busca uma articulação interdisciplinar na abordagem das questóes ambientais. Essa característica evidencia uma mudança de concepção em relação ao processo educativo, sobretudo quanto à precariedade, falta ou mesmo limitação de uma área do conhecimento dar conta da transversalidade que exige a EA e toda a sua complexa gama de conhecimentos.

A ideia de que uma fatia delimitada de conhecimento seria incapaz de impactar com efetividade os problemas ambientais atuais é um indicativo de que há, pelo menos para esse grupo de professores, um processo de reflexão em torno do educar para a vida em sociedade e que a EA pode ser uma importante ferramenta para isso.

\section{Resultados da Etapa 2}

Assim como os dados apresentados pelos questionários foram analisados a partir das informaçôes fornecidas pelos 388 professores do ensino fundamental, as entrevistas concedidas por sete deles foram analisadas pelo programa Alceste, de acordo com Chamon e Chamon (2015) CHAMON, e classificadas em agrupamentos de discursos, a partir dos 
quais foram organizados mapas esquemáticos que sintetizam as classes de significado. Neste artigo foram analisadas apenas duas (2) delas.

A primeira classe é formada pelo perfil mais próximo a sujeitos casados, do sexo masculino, com renda pessoal entre três (3) e cinco (5) salários mínimos e que trabalham apenas um turno na escola como professor II entre um (1) e cinco (5) anos.

\section{Classe 1 (1)}

EDUCACAOA

AMBIENTAL

\section{Mapa esquemático da Classe 1}

Elaborado pelas pesquisadoras.

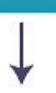

Relação/Homem/Sociedade/Meio Ambiente

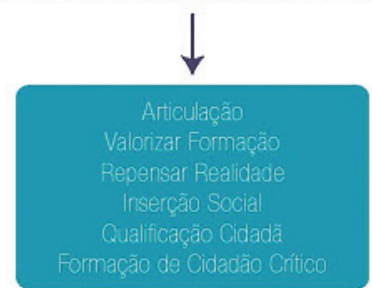

Reponsabilidade compartilhada

Reponsabilidade do professor

Reponsabilidade da escola

\section{Português/Matemática/História/Geografia/Ciências}


A Classe Um (1) agrupou discursos voltados principalmente para o campo filosófico. Esse agrupamento tratou a EA como uma responsabilidade compartilhada, relacionada aos campos político, cultural e ecológico. Nessa classe evidenciam-se as reflexóes dos sujeitos a respeito das provocaçôes que os professores podem fazer aos alunos a partir de contextos e situaçôes cotidianos. Assim, as RS dos professores apontam para o fortalecimento do processo de ação e formação entre professor e alunos como necessidade iminente para as mudanças paradigmáticas. Segundo Reigota (1995, p. 70) "[...] as representaçóes sociais equivalem a um conjunto de princípios construídos interativamente e compartilhados por diferentes grupos que através delas compreendem e transformam a realidade." Dessa forma, denota-se que as representaçóes do grupo de professores do Ensino Fundamental II perpassam os elementos inerentes à sala de aula e partem em busca de parcerias nas diferentes disciplinas para dividir as responsabilidades entre as áreas do conhecimento.

A mudança de paradigmas aparece nos discursos dos docentes como parte de um processo contínuo que envolve a formação de todos os atores da escola: corpo docente e discente, funcionários e gestores. A responsabilidade pela EA, considerado o viés da formação, passa entáo a ser de todos e se torna, inclusive, abordagem fundamental em todas as disciplinas que fazem parte do currículo.

A escola aparece como principal responsável pelas mudanças de postura. Segundo Gadotti (2008 a; 2008 b), o conceito de sustentabilidade na educação pode ter um impacto positivo não só no que se refere aos indivíduos, mas também nas necessárias mudanças do sistema educacional.

A escola e a família são sinalizadas pelos professores como responsáveis pela formação da cidadania. Entretanto, a escola não é vista por eles como continuação da família, mas constituída partir de uma ruptura com os laços familiares, uma vez que a natureza desses grupos sociais é diferente. Os laços que se estabelecem na escola são laços de cidadania; não que a afetividade não deva existir, mas as relaçôes, neste caso, que devem conduzir prioritariamente para práticas políticas e sociais.

A realidade atual exige uma reflexão cada vez menos linear, e isto se produz na inter-relação dos saberes e das práticas coletivas que criam identidades e valores comuns e açóes solidárias 
diante da reapropriação da natureza, numa perspectiva que privilegia o diálogo entre saberes. (JACOBI, 2003, p. 191)

Para Jacobi (2003), a escola é o local propício para contribuir com a formação integral do cidadão, a partir da consciência de uma educação ética, crítica e contínua acerca da EA e da qualidade de vida. Nesse sentido, a escola é pensada como espaço social que privilegia o diálogo interdisciplinar, em uma harmonia entre a prática da disseminação dos saberes e a prática coletiva que deverá criar identidades de valores e açóes solidárias.

Diferentemente da Classe Um (1), a Classe Dois (2) agrupou sujeitos que trazem a discussão sobre a EA de forma mais objetiva, voltada à prática cotidiana característica da sala de aula. Essa Classe é formada pelo perfil mais próximo a sujeitos do sexo feminino, com idade entre 26 e 35 anos, solteiros, com renda pessoal entre dez (10) e quinze (15) salários mínimos, que trabalham três (3) turnos na escola e têm um tempo de profissão como professor no Ensino Fundamental II variando entre cinco (5) e dez (10) anos.

No conjunto de discursos agrupados na Classe Dois (2), a EA é entendida como algo vivenciado na escola e a partir da escola. As RS dos docentes indicam situaçóes pontuais do dia a dia como a importância da organização e da manutenção da limpeza do espaço interno da sala de aula, para que se construa um ambiente saudável. Reigota e Prado (2008) descrevem a EA como ferramenta que permite refletir o cotidiano no qual estão inseridas as pessoas que convivem em um mesmo contexto, sendo afetadas pelos diferentes tipos de interação pelos quais vivenciam suas experiências. Sendo assim, essa classe apresenta um conjunto de informaçóes relevantes no tocante à rotina de cuidados com livros e materiais de uso didático. Relaciona, ainda, os projetos de manutenção e organização das salas à organização de filas para movimentação dentro da escola, pontuando que a colaboração deve ser incorporada por todos os atores da escola. Em consonância com os discursos dos docentes, os PCNs. (BRASIL, 1997, p. 195) apontam:

Cada professor pode contribuir decisivamente ao conseguir explicitar os vínculos de sua área com as questôes ambientais, por meio de uma forma própria de compreensão dessa temática, 


\section{Classe}

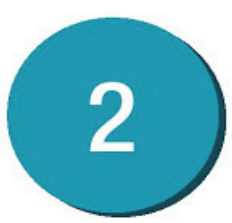

\section{Projetos Educação Ambiental}

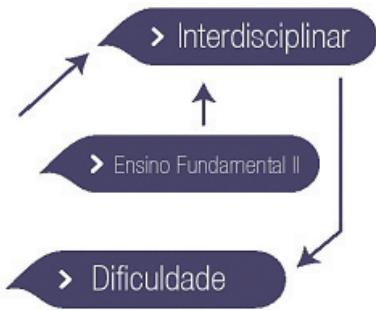

Mudança de postura (escola)

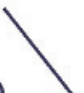

- Não pegar coisas dos outros alunos

- Limpeza de sala

- Organização de sala

- Economia de material

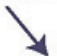

Consciência

Ambiental

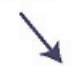

Evitar maltrato aos animais

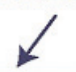

> Reciclagem

Utilizar ações da escola como:

\section{Ações}

R.S. da classe Desvalorizaçăo

docente $\rightarrow$ salarial e do professor

$\rightarrow$ Infraestrutura

Para todo professor 
mento facilitador de mudanças comportamentais, atitudinais e procedimentais em relação à sociedade e ao MA. Expressaram que a EA pode fortalecer os vínculos entre família e escola e favorecer a qualidade de vida das pessoas no convívio escola-sociedade.

\section{Consideraçóes finais}

Mediante a análise dos resultados evidenciou-se que a EA, para que seja eficaz, depende de que o educador vá além do conhecimento específico e compreenda que ela requer uma transformação comportamental. Essa transformação deve ocorrer de forma intrínseca, pois o desejo de mudança deve partir de cada um, cabendo aos professores sensibilizar os alunos para as questóes mais fundamentais. Como a EA traz essa proposta de trabalho, auxiliando a sensibilização dos alunos para transformar seu meio, seus resultados acontecem de maneira gradual e progressiva.

Em ambas as etapas do estudo os professores manifestaram que compreendem a necessidade de desenvolver a EA nas escolas, em âmbito interdisciplinar ou transversal. Compreendem que essa pode ser uma ferramenta crucial a partir da qual possam ocorrer necessárias mudanças paradigmáticas na relação homem e sociedade, ainda mais considerando que há certa facilidade na abordagem dos temas circunscritos à EA. Contudo, mesmo que seja apontada essa facilidade, persiste a necessidade da oferta de melhores subsídios e oportunidades no ambiente escolar para que a EA efetivamente aconteça.

Tanto nos resultados encontrados na primeira etapa deste estudo quanto os verificados na segunda etapa identifica-se a necessidade de continuar o projeto de formaçáo docente nas escolas, haja vista o desejo explicitado pelos professores no que tange à aquisição de conteúdo e direcionamento para desencadear o tema na sala de aula.

Nessa perspectiva, cabe trabalhar pela inserção da temática na agenda anual de trabalho na rede municipal, com programação que motive o grupo a desenvolver açóes relacionadas ao eixo temático relativo à EA, assim como repensar os conteúdos curriculares. Por fim, planejar e desenvolver efetivos programas de formação continuada que motivem o corpo 
docente à busca pela construção do conhecimento e pela formação integral dos alunos.

Após a análise dos dados coletados, evidenciou-se que os resultados obtidos poderão ser utilizados na elaboração das Diretrizes Pedagógicas para Educação Ambiental do Município, a fim de nortear as açóes curriculares na direção da temática da EA.

\section{Referências}

NÓBREGA, Luciana; CASAVECHIA, Talita Mariane. Hora de trabalho pedagógico: desafio e controvérsias. In: BASSO, Ilda; ROCHA, José Carlos Rodrigues; ESQUEDA, Marileide Dias (orgs) Anais [recurso eletrônico] / 2. Simpósio Internacional de Educação, Bauru, SP: USC, 2008. Disponível em: <http://www.usc.br/biblioteca/pdf/ sie_2008_educ_arti_hora_de_trabalho_pedagogico.pdf> Acesso em: 27 nov. 2016.

BRASIL. AGENDA 21. Conferência das Naçôes Unidas sobre o Meio Ambiente e Desenvolvimento. Centro de Documentação e Informação-Coordenação de Publicações: 1995. Disponível em: <http://www.onu.org.br/rio20/img/2012/01/agenda21.pdf > Acesso em: 27 jun. 2015.

BRASIL. Parâmetros Curriculares Nacionais, PCNs, MEIO AMBIENTE, 1997. BRASIL. ProNEA/Educação Ambiental: por um Brasil Sustentável - ProNEA, Marcos Legais e Normativos - 4a Ed-Brasília: Ministério do Meio Ambiente/Ministério da Educação. 2014.

BUSSOLOTTI, J. \& ORTIZ. P. Educação Ambiental para Sustentabilidade. Livro texto para Programa de Educação à distância da Universidade de Taubaté, Taubaté: UNITAU, 2015.

CHAMON, M.A. e CHAMON, E.M.Q.O., Preparando um texto para software ALCESTE. Taubaté: UNITAU - Universidade de Taubaté, Programa de Pós Graduação em Desenvolvimento Humano, 2015 (no prelo).

GADOTTI, M. Educar para a sustentabilidade. Inclusão Social, Brasília, v. 3, n. 1, p. 75-78, out. 2007/mar. 2008 a. Disponível em <http://revista.ibict.br/inclusao/index. php/inclusao/article/viewFile/113/122> Acesso em: 19/05/2015.

GADOTTI,M. Educar para a sustentabilidade: uma contribuição à década da educação para o desenvolvimento sustentável. São Paulo: Editora e Livraria Instituto Paulo Freire, 2008 b.

JACOBI, Pedro. Educação ambiental, cidadania e sustentabilidade. Cad. Pesqui., São Paulo, n. 118, p. 189-206, Mar. 2003. 
Discponível em <http://www.scielo.br/scielo.php?script=sci_arttext\&pid=S0100$15742003000100008 \& \operatorname{lng}=$ en $\& n r m=$ iso $>$. Acesso em: 24/11/2015.

LOUREIRO, D. G. Educação Ambiental no Ensino Fundamental: um estudo da prática pedagógica em uma escola municipal de palmas - TO. 2009. 88 f. Dissertaçáo (Mestrado) - Curso de Pós-Graduação em Educação, Universidade de Brasília, Brasília, 2009.

MORIN, E. Os sete saberes necessarios à educação do futuro. Brasília (DF): Cortez, UNESCO, 2000.

MOSCOVICI, S. Representaçôes Sociais: investigaçôes sem psicologia social : editado em ingles por Gerard Duveen : traduzido do inglês por Pedrinho A. Guareshi. 8, ed.- Petrópolis, RJ : Vozes, 2011.

NÓBREGA, Luciana; CASAVECHIA, Talita Mariane. Hora de trabalho pedagógico: desafio e controvérsias. In: BASSO, Ilda; ROCHA, José Carlos Rodrigues; ESQUEDA, Marileide Dias (orgs) Anais [recurso eletrônico] / 2. Simpósio Internacional de Educação, Bauru, SP: USC, 2008. Disponível em: <http://www.usc.br/biblioteca/pdf/ sie_2008_educ_arti_hora_de_trabalho_pedagogico.pdf> Acesso em: 27 nov. 2016.

REIGOTA, M. A floresta e a escola: por uma educação ambiental pós-moderna. 4. Ed. São Paulo: Cortez, 2011.

REIGOTA,M. . Meio ambiente e representação social. São Paulo: Cortez, 1995.

REIGOTA, M., PRADO, B.H.S. Educação Ambiental: utopia e práxis. São Paulo: Cortez, 2008.

SETUBAL, M.A. Educação e sustentabilidade: princípios e valores para a formação de educadores. São Paulo; Petrópolis, 2015.

Recebido em Io abr. 2017 / Aprovado em I5 jan. 2018

Para referenciar este texto:

MONTEIRO, I. F. C.; MONTEIRO, P. D. E. B. S. C. O. A educação a mbiental nas representaçóes sociais de professores e a importância do Projeto Sala Verde. EccoS-Revista Científica, São Paulo, n. 48, p. 20I-218. jan./mar. 20I9. Disponível em: <https://doi.org/I0.5585/EccoS.n48.7285>. 